\title{
BORIS SCHNAIDERMAN EM TEIAS CULTURAIS E AFETIVAS
}

\author{
Evelina Hoisel ${ }^{1}$
}

\begin{abstract}
Resumo: Esta leitura procura refletir sobre os investimentos intelectuais e afetivos de Boris Schnaiderman que movimentam os trânsitos culturais Brasil e Rússia, Verifica-se como a sua trajetória de tradutor intercultural desenvolveuse no sentido de construir pontes de longo alcance que, com o passar dos anos, constituíram-se como um entrelugar marcado pelo saber e pela afetividade que passa a permear esses contatos. Observa-se também como Jerusa Pires Ferreira contracena com Boris Schnaiderman outra potente face das traduções culturais Brasil-Rússia, pelo viés da oralidade, dedicando-se ao estudo do conto russo no sertão baiano e construindo teias culturais duplamente marcadas pelo saber e pela afetividade.
\end{abstract}

Palavras-Chave: Boris Schnaiderman. Trânsitos culturais. Brasil-Rússia.

\section{BORIS SCHNAIDERMAN IN CULTURAL AND AFFECTIVE WEBS}

\begin{abstract}
This reading seeks to reflect on the intellectual and affective investments of Boris Schnaiderman that move cultural transits between Brazil and Russia. One can see how his career as an intercultural translator developed in the sense of building long-term bridges that, over the years, have been constituted as an in-between marked by the knowledge and affection that permeate these contacts. It is also observed how Jerusa Pires Ferreira plays with Boris Schnaiderman another potent face of Brazil-Russia cultural translations, through oral bias, dedicated to the study of the Russian tale in the Bahian hinterland and the construction of cultural networks doubly marked by knowledge and affection.
\end{abstract}

Keywords: Boris Schnaiderman. Cultural transits. Brazil-Russia.

No sentido de elucidar os investimentos intelectuais e afetivos de Boris Schnaiderman que movimentam os trânsitos culturais Brasil e Rússia, recorro inicialmente ao seu texto datado de 1960, "Incompreensão mútua", publicado na coletânea Projeções - Rússia- Brasil - Itália (SCHNAIDERMAN, 1978, p. 17-21), no qual ele declara que as relações da Rússia com o Ocidente sempre foram prejudicadas pelos preconceitos, pelas impressões superficiais,

\footnotetext{
${ }^{1}$ Evelina Hoisel é professora Titular da Universidade Federal da Bahia, bolsista CNPq 1D. Possui livros e artigos publicados na área da Teoria da Literatura e da Literatura Comparada.
} 
pela hostilidade mútua - provocada pelo desconhecimento e incompreensão dessas culturas - e pela falta de um esforço para penetrar mais a fundo na mentalidade do outro.

Boris Schnaiderman denuncia uma ideia preconcebida de que o mundo russo era algo impenetrável, falando-se constantemente dos "mistérios da alma eslava”, ressaltando-se a impossibilidade de um ocidental ter acesso a esse mundo, enquanto os russos estariam dotados de uma extraordinária capacidade para assimilar a cultura dos demais povos. Esclarece como escritores russos, a exemplo de Dostoiévski e de Tolstói, expressaram sua condenação ao mundo ocidental e burguês, em nome de uma concepção humanística, outras vezes, acercaram-se do mundo ocidental com visões "muito estreitas, cuja debilidade a história se encarregaria de demonstrar em poucos anos" (SCHNAIDERMAN, 1978, p. 20).

Schnaiderman observa, todavia, que as excelentes traduções da literatura russa no ocidente demonstraram que essas relações não eram tão impenetráveis, assinalando que o referido preconceito foi bastante combatido nos últimos anos na União Soviética. Conclui o ensaio "Incompreensão mútua", de 1960, afirmando que apesar desses aspectos, "ambas as partes têm muito a aprender no sentido de um espírito mais amplo e generoso, e mais despido de preconceitos" (SCHNAIDERMAN, 1978, p. 21).

Em outro ensaio da mesma coletânea, intitulado "Caminhos da compreensão", datado de 1962, Schnaiderman desloca o foco dos comentários interculturais, agora para as relações Rússia e Brasil, chamando a atenção para a maneira exótica como o Brasil e a América Latina em geral foram vistos na Rússia. Na sua avaliação, os próprios escritores russos propagaram essa concepção, citando dentre outros, Maiakóvski, em O Percevejo, que faz chegar a Moscou uma aeronave com viajantes brasileiros, em um acontecimento "feérico e descomunal" para os anos de 1928, flagrando-se assim o desconhecimento de aspectos corriqueiros da vida brasileira naquela época.

Posteriormente, expande-se na Rússia o interesse pela literatura brasileira, privilegiando-se, contudo, uma temática política e imediatista, justificando-se por esta via a tradução de textos que, segundo Schnaiderman, não eram representativos da literatura brasileira, mas tematizavam questões ideológicas que mantinham afinidades com o realismo socialista /crítico em 
voga na época stalinista. Esses textos, contudo, não são referenciados pelo autor no artigo citado, embora possamos apontar os autores aos quais ele se refere.

Apesar dessas incongruências, esse intelectual entre fronteias anunciava fecundas possibilidades para os estudos brasileiros na Rússia, bem como para uma melhor compreensão entre as duas culturas. A sua trajetória como tradutor intercultural desenvolve-se no sentido de confirmar outras possibilidades de relacionamentos, construindo pontes de longo alcance que, com o passar dos anos, constituíram-se como um entre-lugar marcado pelo saber e pela afetividade que passa a permear esses contatos interculturais essas teias culturais.

Além de um potente trabalho de tradução de escritores russos, tarefa exercida até o final de uma vida de noventa e nove anos, marcado pelo gesto inovador de traduzir diretamente do russo para o português - e não de outras línguas como o francês, como se procedia antes, Boris Shaneiderman promoveu a renovação de concepções teóricas, de aberturas conceituais para o pensamento experimental, introduzindo no Brasil a semiótica Russa, o formalismo russo, além de pensadores da cultura como Iúri Lotman, Mikhail Bakhtin, Roman Jakobson, Kristina Pomorska, dentre tantos outros Jakobson e Pomorska estiveram no Brasil a convite de Schnaiderman. Por sua vez, viveu intensamente a experimentação das vanguardas russas com Augusto de Campos e Haroldo de Campos, com os quais traduziu e publicou Poemas de Maiakovski(1967) e Poesia russa moderna (1968).

Ao se debruçar sobre a literatura e cultura russas, Boris Schnaiderman adotou como critério principal da sua avaliação crítica a inovação estética. Nesse sentido, pode-se entender a sua predileção pelo estudo das vanguardas do século vinte e também pela literatura russa pós1917. Bruno Gomide, em um ensaio publicado em 2018, na Revista Literatura e sociedade, edição especial em homenagem ao centenário de Boris Schnaiderman, observa:

Boris Schnaiderman foi um pioneiro completo da divulgação e análise da literatura russa pós-1917, como arte literária. Excetuado Maiakóvski, alvo de incursões críticas e tradutórias entre os anos 20 e 50, a literatura 
soviética foi uma descoberta de Boris Schnaiderman, um gesto crítico que promoveu um avanço gigantesco em relação ao estado de coisas, inclusive em relação ao próprio Maiakóvski, o eixo em torno do qual girava o mundo do crítico russo-brasileiro. Se na prosa o paradigma era dado por Bábel, na poesia, e para a experiência cultural russa do século vinte de modo geral, o farol era mesmo o autor da Nuvem de calças. Os dois, Bábel e Maiakóvski, demonstravam que a revolução e a renovação literária podiam caminhar juntas (GOMIDE, 2018, p. 29).

O especialista em eslavística prossegue enfatizando a importância da crítica de Schnaiderman no panorama da cultura brasileira. Afirma Bruno Gomide: "O projeto crítico de Boris teve consequências para a construção de um olhar brasileiro sobre o século vinte russo, lido através de Maiakóvski (como o dezenove o é pelo prisma de Dostoiévski)" (GOMIDE, 2018, p. 29).

Além dos autores traduzidos durante sua longa trajetória como tradutor interlingual - aproximadamente dos anos 1950 até o ano de sua morte 2016 - vertendo diretamente do russo para o português Dostoievski, Tolstói, Puchkin, Gorki, Tchékhov, Guenádi, Maiakóviski, Bábel e tantos outros, Boris construiu um panorama da literatura russa pós-1917, divulgando no Brasil, por meio do jornalismo cultural, nomes de escritores que circulavam no cenário literário da Rússia. É importante lembrar que o acesso à bibliografia sobre a Rússia era bastante difícil e, muitas vezes, as escolhas do críticos e tradutor eram ditadas pelo material disponível.

A profunda escavação na literatura e na cultura pós-1917 está registrada na coletânea de ensaios Os escombros e o mito: a cultura e o fim da união soviética (1997). Nesse livro, Schnaiderman difunde uma profusão de imagens da Rússia desde a revolução de outubro de 1917 até a glasnost e pierestróika, em 1985. É notável o conhecimento disseminado nos trinta ensaios sobre o contexto cultural da Rússia durante esse longo período. O livro representa um projeto monumental de resgate de nomes e de obras que permaneceram no esconderijo do "depósito especial", o spietrkhram. A abertura deste "depósito especial" revelou a existência de uma espécie de "sítio arqueológico", nas palavras de Paulo Bezerra, da memória cultural soviética que o stalinismo havia condenado ao esquecimento. 
O objetivo da publicação é explicitado em diversos trechos. Trata-se de uma história que ainda não tinha sido totalmente narrada (é importante frisar que o livro é de 1997) e Schnaiderman quer contribuir para que "tudo venha a tona, tudo apareça", no sentido de promover a recuperação da memória cultural e a revisão de diversas noções sobre a cultura russa a partir de 1917. Além disso, para Schnaiderman, como um intelectual humanista, estes acontecimentos possibilitam a compreensão da "condição humana" (SCHNAIDERMAN, 1997, p. 14), e esse aspecto é reiteradamente afirmado quando ele declara a sua perplexidade diante da paradoxal condição humana, em meio às vicissitudes históricas dos fatos retirados dos arquivos e recuperados dos escombros. O fio condutor de suas investigações é a tentativa de compreender o outubro de 1917 como o grande acontecimento do século 20 e como uma catástrofe social e cultural.

Os ensaios que compõem a coletânea Os escombros e o mito resultaram de pesquisas em bibliotecas alemãs, durante cinco meses, em 1988, e posteriormente, em 1992, na Universidade de Londres, na Inglaterra, onde Schnaiderman tinha acesso aos materiais russos, após uma semana de divulgação na mídia, como acontecia também nas bibliotecas alemãs durante o período em que ele esteve em Berlim. As pesquisas ainda se efetivaram em Bloomington, Indiana, junto à universidade, cuja biblioteca de eslavística foi crucial para compor o repertório de informações necessárias para a reconstrução das memórias e das reflexões desenvolvidas.

Tanto os jornais quanto as revistas permitiram acompanhar as transformações que se processavam no interior do mundo russo e se tornaram porta voz da glasnost. A leitura de Schnaiderman pretende atacar qualquer ocultamento dos registros encontrados para revelar simultaneamente o "esmagamento brutal da cultura", mas também "as formas subterrâneas de manifestação" e "de resistência" (SCHNAIDERMAN, 1997, p. 16) que vinham à tona com o abrandamento no regime, exibindo-se assim, neste duplo gesto, os paradoxos que caracterizaram a derrocada e a preservação de um monumental acervo cultural.

Os ensaios impressionam pelo conhecimento e pela descrição minuciosa dos episódios relatados e pela erudição com que Schnaiderman aborda os temas em todas as áreas da cultura, formando um imenso 
caleidoscópio através do qual se projetam inúmeros personagens romancistas, poetas, dramaturgos, homens de teatro, pintores, cineastas etc , um volume gigantesco de obras, de episódios de censuras e de fiscalização sobre as obras, máquinas de triturar projetos e pensamentos, o clima de coação, prisões, catástrofes familiares, mortes solitárias e coletivas, em que se registra além da morte física, o horror da morte civil.

Revela também contrabandos ideológicos, falsificação da história e envernizamento dos fatos, estratégias de resistência e de sobrevivência, principalmente nos trabalhos forçados na Sibéria, conflitos dos escritores entre duas línguas (como Nabokov), que produziram fora da Rússia, e cujas obras dramatizam a situação vivida sob um regime opressivo. Analisa ainda o humor, o cômico e o grotesco por meio dos quais se encenavam o absurdo, o nonsense, o ilógico das situações vivenciadas, fazendo-se do riso um importante e surpreendente fato da vida cultural Russa a partir de 1917. Pulsam as imagens de vida e de resistência no subterrâneo dos acontecimentos, nos quais se destacam as escritas de mulheres que deixaram marcas profundas na cultura de seu tempo. Schnaiderman afirma, em relação a este aspecto: "Realmente, é difícil encontrar outro período da história em que tenham aparecido tantas mulheres extraordinárias e que deixaram marca tão profunda na cultura de seu tempo" (SCHNAIDERMAN, 1997, p. 110).

Por sua vez, projetam-se as imagens que afirmam a glorificação das conquistas realizadas pela Revolução de 1917, a confiança no partido comunista, o fervor e a admiração por Stalin que, segundo Schnaiderman, constitui-se no grande mito político que ainda precisa ser compreendido para que se tenha uma visão adequada da época daquele que foi considerado como “' pai e irmão mais velho da todos' , aquele que engendra uma clara e viçosa humanidade, uma outra natureza, um outro coração" (SCHNAIDERMAN, 1997, p. 113).

As contradições das imagens que pulam e saltam dos arquivos da história, a riqueza dos materiais examinados, a complexidade dos escritos, tudo isso reserva muita surpresa para o pesquisador, por isso a sua sensação de espanto e de perplexidade face aos registros e documentos consultados. O acervo das áreas inventariadas por Schnaiderman é vastíssimo: o amplo repertório da literatura (citando inúmeros romancistas, poetas, dramaturgos), 
textos de testemunhos, diários, teorias críticas, jornalismo, história, filosofia, artes plásticas, teatro, cinema, ciência, natureza/ecologia. E, ao tratar de todos os temas, a profusão de informações e de questionamento sobre os dados em análise surpreendem também o leitor.

Mais do que um olhar crítico e distanciado de um observador arguto e perspicaz, o que se observa nos trinta capítulos é que os assuntos brotam da visão de um sujeito com uma lucidez dolorosa, que tem uma profunda convivência e uma penetrante relação com a cultura russa ao longo dos anos, mesmo estando distante, Entretanto Schnaiderman está constantemente a colocar em suspensão o material e os dados com os quais trabalha. Em alguns trechos, ele anota a sua desconfiança em relação ao material investigado, interrogando: "A grande quantidade de depoimentos faz surgir mais claramente o problema: em que medida podemos confiar no testemunho dos que viveram determinados acontecimentos históricos?" (SCHNAIDERMAN, 1997, p. 120).

Schnaiderman esclarece constantemente a sua postura - podemos dizer, a sua metodologia de abordagem - diante das imagens dos escombros e do mito, ao registrar que: "A tragédia de nosso século não pode ser apreendida por um só ponto de vista" (SCHNAIDERMAN, 1997, p. 121). "Enfim, a 'resssurreição' de textos, com muita frequência, foi um processo nada pacífico, que pôs em confronto diferentes tendências e opiniões, fazendo vir à tona um mundo de contradições e conflitos" (SCHNAIDERMAN, 1997, p. 90).

Nas abordagens efetuadas sobre as diversas manifestações culturais da Rússia em Os escombros e o mito, pode-se reconhecer a presença do crítico e do teórico da literatura na leveza da escrita ensaística e documental do tradutor russo - duplamente tradutor: de língua e de cultura a redesenhar o monumental painel político cultural da Rússia, desde a Revolução de 1917 até o início da glasnost e da perestroika, em 1985. Na sua trajetória prevalece uma ética que afirma como um dos traços fundamentais do perfil do intelectual a resistência, o dever moral de falar, de agir sem abdicar de seu saber em relação aos fatos nos quais esteve diretamente envolvido, ou conhece como resultado de sua tarefa de pesquisador, como ele faz em Os escombros e o mito. 
Com esta mesma postura ética, Schnaiderman transforma a sua experiência entre trincheiras como integrante da Força Expedicionária Brasileira, lutando na Itália durante a segunda Guerra Mundial, em 1944, em um saber que precisa ser compartilhado, no sentido de promover um outro olhar sobre essa cena da guerra, seja assumindo uma escrita biográfica, seja ficcionalizando as suas vivências, e expondo as tensões turbinadas na subjetividade de cada pracinha, por meio de personagens ficcionalizados, em Guerra em Surdina (1964) voltando ao mesmo tema em Caderno Italiano (2015).

Pode-se perceber também o seu lócus de atuação pedagógica nas lições disseminadas através das escavações da história e da reconstrução dos escombros. São muitas as aprendizagens distribuídas nas malhas da letra, principalmente para aqueles que já vivenciaram outras formas de repressão ou que vivem em tempos sombrios, sob o risco de outras formas de violência e de barbárie, numa afirmação de que é possível reinventar a história e não repetir modelos já vivenciados.

Os contatos culturais são flagrados por este intelectual entre fronteiras de forma dialógica, generosa, assumindo a postura de quem está à frente de sua época e quer captar os acontecimentos por um viés ainda não estabelecido. Seu olhar sobre a Rússia enfatiza constantemente o peso da tradição de um mundo sólido, que repousa sobre pesados alicerces e que pesa também sobre quem procura um caminho novo, uma forma de expressão diferente e transgressiva, valores destacados constantemente nos diversos ensaios para caracterizar tanto a produção literária e artística, como a tradução interlingual.

Boris Schnaiderman assinala nas suas reflexões as marcas de sua simpatia pelo híbrido, pelo contraditório e paradoxal das relações de tradução intercultural. A sua própria biografia constitui-se como marca dessa multiplicidade, definindo sua trajetória intelectual como signo de tradução, fazendo das migrações - geográficas e discursivas - uma potente possibilidade de tensionar, articular e movimentar culturas.

Posso então compreender o afeto com que a Rússia celebrou a sua dedicação de quase um século de vida difundindo as imagens daquele país para o Brasil e para o mundo. O reconhecimento institucional deu-se pela 
concessão da medalha Putkin a Boris Schnaiderman pelo governo russo. O afetivo pode ser aferido pelo ardor amoroso das dedicatórias com que o poeta Guenádi Aigui presenteou Boris Schnaiderman e sua esposa, Jerusa Pires Ferreira, companheira durante mais de vinte anos desse intelectual russobrasileiro.

As dedicatórias que Boris trouxe a público em um dos últimos livros, escrito em parceria com Jerusa, Guenádi Aigui: silêncio e clamor (2010) expõem o afeto flamejante e transbordante da intimidade de uma relação de amigos, considerados irmãos de sangue, de laços inseparáveis, embora geograficamente tão distantes. Os poemas-dedicatórias datam de julho de 1987 - "Círculo de Amor" -; de junho de 1983 - "Rosa do silêncio" - e de 1991 "Dedicatória", todos eles escritos em momentos de encontros e reencontros dos amigos na Rússia.

Os textos são perpassados pelos temas que circulam nas poesias de Guenádi - o silêncio, o sofrimento, a impotência, mas também da resistência vital. É o sofrimento que une os amigos - sofrimento resultante de vivências semelhantes: Guenádi, na Rússia, sentindo as agruras de um regime repressor e Schnaiderman, tendo que sair do seu país, porém compartilhando na distancia, com firmeza e constância as dores de seus irmãos, impregnado de uma história que é também a do poeta Guenádi.

A poesia não só irmana, ela também promove para o leitor/tradutor uma travessia pelo terreno pantanoso no qual se situa o poeta. Pode-se bem compreender o elogio da amizade que dá corpo a esses textos, envolvendo três intelectuais da segunda metade do século vinte e do século vinte e um: Guenádi, Schnaiderman e Jerusa, todos eles amorosamente enlaçados pela teia das palavras do clamor poético de Guenádi Aigui. Transcrevo aqui o poema "Dedicatória":

Dedicatória $^{2}$

A meu querido Boris -

\footnotetext{
2 "O texto foi escrito por Aigui, com sua letra tão firme, tão bela, no frontispício do seu livro Zdiés (Aqui), o primeiro publicado na Rússia (1991), após tantos anos de silêncio forçado. Vacilei muito de traduzi-lo para este livro, mas acabei achando que o leitor tem o direito de conhecer a imensidão de carinho e humanidade que havia naquele homem. Boris Schnaiderman" (SCHNAIDERMAN; FERREIRA, 2010, p. 134) Os dois outros poemas que se encontram no livro tem tradução de Boris com Haroldo de Campos.
} 


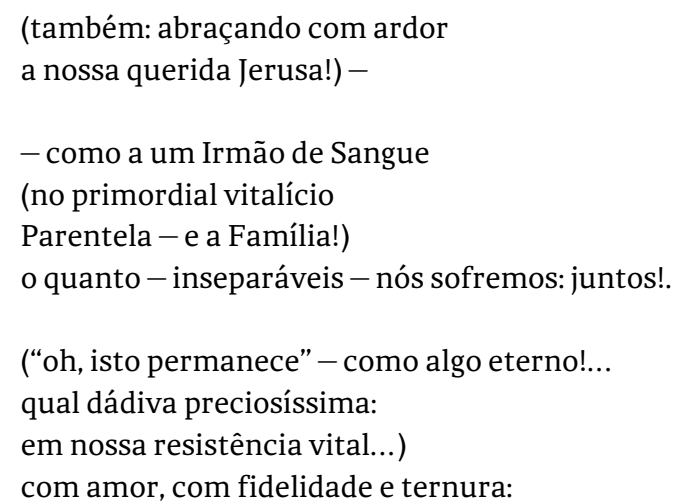

Guena

(SCHNAIDERMAN; FERREIRA, 2010, p. 134)

O interesse de Boris e de Jerusa pela poesia de Guenádi recobre vertentes distintas. A predileção de Boris Schnaiderman pelas vanguardas artísticas e pela literatura pós-1917 promove o fascínio pelos textos de Guenádi, e desse encontro se estabelece uma relação intercultural com forte repercussão internacional para a divulgação da obra desse poeta tchuvaches, silenciado pelo stalinismo, por ser considerado hostil ao regime, uma vez que subvertia os fundamentos do realismo crítico. Boris não só traduziu a sua poesia, como participou de uma rede internacional de tradutores e de estudiosos de Guenádi Aigui, responsável pela divulgação de sua obra no ocidente, ainda em 1964.

O interesse de Jerusa Pires Ferreira vem primordialmente pela veia da oralidade tão presente nessa poesia. Guenádi Aigui exerce sua arte entre duas correntes que dialogavam na Rússia de então: tradição e vanguarda, as quais constituíram um importante projeto revolucionário do século 20. Por sua vez, pertencer aos tchuvaches, detentores de um vasto conjunto de lendas, cantos orais, práticas mágicas ritualizadas era também pertencer a uma tradição, mas, simultaneamente, ele estava inserido em um sistema político oficial sufocante. A poesia de Guenádi, segundo a especialista em oralidade, falecida em abril de 2019, na Bahia, recupera o mundo desses conhecimentos que atravessam o próprio corpo do poeta. Na poesia de 
Guenádi Aigui, afirma Jerusa, a palavra que evoca a oralidade no escrito cria e reinstala ancestralidades e seus ritmos.

Jerusa amplia assim o foco de observação da poesia de Guenádi e se torna uma parceira de Boris Schnaiderman no processo de tradução e difusão cultural Rússia Brasil. Pelo viés da oralidade, ela dedicou-se ao estudo do conto russo no sertão baiano, tema do seu livro Matrizes impressas do oral: conto russo no sertão (2014), no qual atesta a presença de lendas e contos russos - como a do Pássaro de fogo - no folheto de Severino Borges da Silva, Princesa Maricruz e o cavaleiro do Ar(s.d.)

Jerusa Pires Ferreira contracena com Boris Schnaiderman outra potente face das traduções interculturais Brasil-Rússia, dois polos geográficos e culturais distantes, mas interrelacionados por vozes provenientes de muitos fios da cultura. Com essas colocações, presto aqui a minha homenagem à essa "Rosa chamejante do Brasil" que se encantou em estrita consonância com a magia das tradições populares que ela tanto amava e que, com Boris Schnaiderman, desenvolveu um potente trabalho de difusão cultural na Rússia e no Brasil, construindo espaços duplamente marcados pelo saber e pela afetividade.

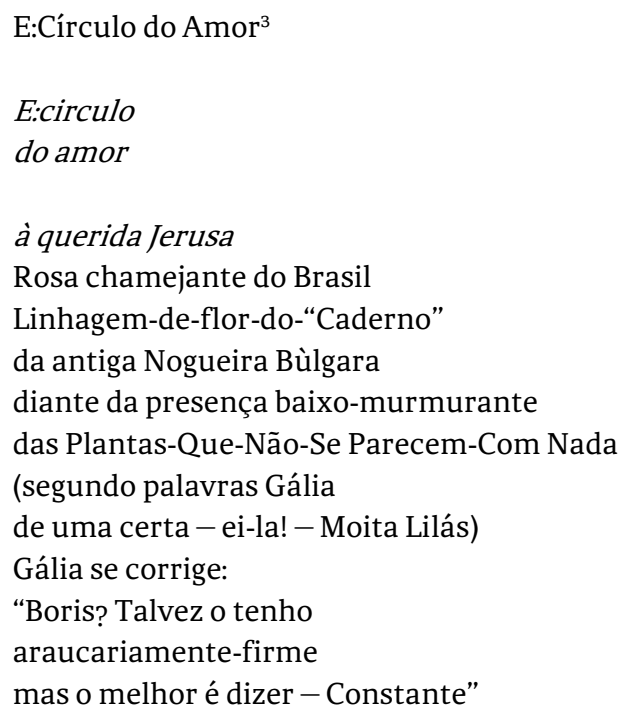

\footnotetext{
3 Poema escrito em casa do poeta, em Moscou, por ocasião da visita de Boris Schnaiderman e Jerusa Pires Ferreira. 18 de julho de 1987 (tradução de Haroldo de Campos e Boris Schnaiderman).
} 
com amor

Aigui

(SCHNAIDERMAN; FERREIRA:2010, p. 130)

\section{Referências}

BORGES, Severino (s.d.). A princesa Maricruz e o Cavaleiro do Ar. [s.n.]

COHN, Sergio. Boris Schnaiderman. Rio de Janeiro: Beco do Azougue, 2010.

GOMIDE, Bruno. Boris Schnaiderman. In: Revista Literatura e sociedade. Edição Especial. N. 26. São Paulo: USP, p. 22-36, 2018.

GOMIDE, Bruno. Maiakósvski na rua do Ouvidor.a literatura russa e o Estado Novo. São Paulo: EDUSP, 2018.

FERREIRA, Jerusa Pires. Matrizes impressas do oral: conto russo no sertão. Cotia: Ateliê Editorial, 2014.

FERREIRA, Jerusa Pires \& BERNARDINI, Aurora Fornoni. Mitopoéticas: da Rússia às Américas. São Paulo: Associação Editorial Humânitas, 2006.

SCHNAIDERMAN, Boris. Caderno Italiano. São Paulo: Perspectiva, 2015.

SCHNAIDERMAN, Boris. Tradução: ato desmedido. São Paulo: Perspectiva, 2011.

SCHNAIDERMAN, Boris. Os escombros e o mito: a cultura e o fim da União Soviética. São Paulo, Companhia das Letras, 1997.

SCHNAIDERMAN, Boris. Turbilhão e semente: ensaios sobre Dostoiévski e Bakhtin. São Paulo: Duas Cidades, 1983.

SCHNAIDERMAN, Boris. Dostoiévski prosa poesia. São Paulo: Perspectiva, 1982.

SCHNAIDERMAN, Boris. Projeções - Rússia- Brasil - Itália. São Paulo: Perspectiva, 1978.

SCHNAIDERMAN, Boris. A poética de Maiakóvski através de sua prosa. São Paulo: Perspectiva, 1971.

SCHNAIDERMAN, Boris. Guerra em Surdina. Rio de Janeiro: Civilização Brasileira, 1964. 
BORIS SCHNAIDERMAN EM TEIAS CULTURAIS E AFETIVAS

SCHNAIDERMAN, Boris; CAMPOS, Augusto; CAMPOS, Haroldo de. Maiakóvski: poemas. São Paulo: Perspectiva, 1967.

SCHNAIDERMAN, Boris; CAMPOS, Augusto; CAMPOS, Haroldo de. Poesia russa moderna. Rio de Janeiro: Editora Civilização Brasileira, 1968.

SCHNAIDERMAN, Boris. FERREIRA, Jerusa Pires. (Org.). Guenádi Aigui: silêncio e clamor, São Paulo: Perspectiva, 2010.

Recebido em 20 de novembro de 2020

Aceito em 15 de dezembro de 2020 